\title{
Procedure for granulocyte collection performed at the Blood Centre of the Faculty Hospital Ostrava
}

\author{
Zuzana Cermakovaa,b, Sarka Blahutovaa ${ }^{b}$, Tomas Papajikc, Dana Galuszkova ${ }^{d}$, Jaromir Hubacekc, Martina Sommerova ${ }^{b}$
}

Background. Granulocyte apheresis is a safe and effective method for granulocyte collection. We present a five year experience (2006-2010) of the Blood Center, Faculty Hospital Ostrava, Czech Republic. Donor granulocyte transfusion is one treatment option for haemato-oncology patients with severe neutropenia complicated by bacterial/fungal infections unresponsive to standard antibiotic/antifungal treatment. In this study, we describe the experiences of the Blood Centre at the Faculty Hospital in Ostrava of granulocyte apheresis.

Methods and Results. A total of 149 granulocyte units were collected for 33 patients from the Department of Haematooncology, University Hospital Olomouc, over a 5-year period (2006-2010). Information on donor selection, laboratory screening, mobilization regimen and granulocyte yield was obtained and analyzed. All mandatory screening tests for infection markers, $\mathrm{ABO}$ and $\mathrm{Rh}$ and abnormal erythrocyte antibodies were performed. The cytomegalovirus status of the donors was not investigated. Steroids were the only mobilization regimen used, and were generally well accepted. The mean granulocyte yield was $12.6 \times 10^{\%}$ /per transfusion unit (range 5.4-30.3). All granulocyte concentrates were irradiated and transfused according to $\mathrm{ABO}$ Rh compatibility within $24 \mathrm{~h}$ after collection.

Conclusion. Based on our experience, granulocytapheresis is a safe and effective method for obtaining granulocytes but the yield can be significantly influenced by other variables. From the recipients' perspective, the use of donor granulocytes supports an effective therapeutic modality.

Key words: granulocyte apheresis, donor selection, mobilization regimen

Received: November 9, 2011; Accepted with revision: July 4, 2012; Available online: November 1, 2012 http://dx.doi.org/10.5507/bp.2012.071

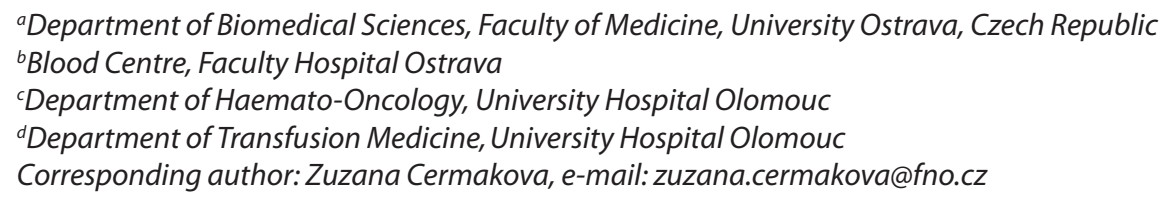

\section{INTRODUCTION}

Transfusions of allogeneic granulocytes are indicated in immunocompromised patients with severe neutropenia whose status is complicated by bacterial/fungal infection unresponsive to standard antibiotic/antifungal therapy. Other indications are primary (congenital) or secondary diseases with neutrophil dysfunction. The granulocyte product contains granulocytes suspended in plasma and is obtained by apheresis from a single donor using automated cell-separation equipment ${ }^{1}$. Sedimentation agents such as hydroxyethyl starch (HES) or low-molecular-weight starch (Pentastarch) are used to improve the separation of leukocytes from erythrocytes. Various mobilization regimens are used to mobilize donor granulocytes, including filgrastim (G-CSF), a combination of G-CSF and corticosteroids, and corticosteroids alone. Tests for $\mathrm{AB} 0$ and $\mathrm{RhD}$ groups, abnormal erythrocyte antibodies, human immunodeficiency virus, hepatitis $\mathrm{C}$ virus (HCV), HBV and syphilis are mandatory. Granulocyte concentrates must be irradiated and transfused as soon as possible after collection. In this study, we present the results of 5 year's experience of granulocyte concentrate collection.

\section{MATERIAL AND METHODS}

A total of 149 granulocyte units were prepared for 33 patients from the Department of Haemato-oncology, University Hospital Olomouc. Data were obtained for the 5-year period from 2006-2010. Each patient received a mean of 4.5 transfusion units (TU) of granulocytes for the diagnoses indicated in Table 1.

Table 1. Diagnoses of recipients of granulocyte transfusions from 2006-2010.

\begin{tabular}{lc}
\hline Diagnosis & Number of patients \\
\hline Acute myeloid leukaemia & 20 \\
Chronic myeloid leukaemia & 2 \\
Myelodysplastic syndrome & 2 \\
Hodgkin's lymphoma & 3 \\
Acute lymphoblastic leukaemia & 5 \\
Aplastic anaemia & 1 \\
\hline
\end{tabular}

Granulocyte donors were obtained from a pool of healthy blood donors with previous experience of apher- 
esis collection (usually recruited from plateletapheresis donors). Granulocytes were collected once every 6 months. Czech law only allows the use of G-CSF for related donors; mobilization in unrelated donors was thus achieved using corticosteroids alone, with an infusion of $40 \mathrm{mg}$ methylprednisolone in $100 \mathrm{~mL} 0.9 \%$ sodium citrate $4-5 \mathrm{~h}$ before collection. No adverse events were reported, except for fatigue within $24 \mathrm{~h}$ after collection. Donors were not tested for cytomegalovirus (CMV) status because the incidence of donor CMV positivity is high (about 90\%) and may change.

High-molecular-weight HES 10\% (molecular weight $200.000 \mathrm{kDa}$ ) was used to enhance granulocyte collection. All donors underwent mandatory tests for human

Table 2. Patient age and number of granulocyte units transfused per patient.

\begin{tabular}{lcc}
\hline & $\begin{array}{c}\text { Patient age } \\
\text { (years) }\end{array}$ & $\begin{array}{c}\text { Number of granulocyte units } \\
\text { transfused per patient }\end{array}$ \\
\hline Mean & 47 & 6 \\
Range & $22-64$ & $1-14$ \\
\hline
\end{tabular}

immunodeficiency virus, hepatitis B virus (HBV), HCV, syphilis, AB0 and Rh and abnormal erythrocyte antibodies. Red blood cell cross-matching between donor and patient was done before granulocytapheresis as granulocyte concentrates contain a significant number of red blood cells. All granulocytapheresis procedures were carried out using a Cobe Spectra separator (Caridian BCT, USA) and all granulocyte concentrates were irradiated after collection.

Blood counts were taken before and after mobilization, with a focus on donor leukocyte counts and normal blood counts. Regarding granulocytes, we focused on the haematocrit per granulocyte TU (to determine the correlation between haematocrit and yield), and yield after collection. MedCalc (MedCalc Software, Belgium) was used to analyze the correlation between haematocrit and yield.

\section{RESULTS}

The results are summarized in Tables 2-6 and in Fig. 1-3.

Table 3. Donor peripheral blood leukocyte and neutrophil counts before and after corticosteroid stimulation.

\begin{tabular}{lcccc}
\hline & $\begin{array}{c}\text { Leukocytes before } \\
\text { collection } \\
\left(10^{9} / \mathrm{L}\right)\end{array}$ & $\begin{array}{c}\text { Leukocytes after } \\
\text { collection } \\
\left(10^{9} / \mathrm{L}\right)\end{array}$ & $\begin{array}{c}\text { Neutrophils before } \\
\text { collection } \\
(\%)\end{array}$ & $\begin{array}{c}\text { Neutrophils } \\
\text { after collection } \\
(\%)\end{array}$ \\
\hline Mean & 6.2 & 7.6 & 54.0 & 88.0 \\
Range & $2.7-10.6$ & $3.8-14.5$ & $36.0-75.0$ & $45.0-5.0$ \\
\hline
\end{tabular}

Table 4. Haematocrit per granulocyte unit.

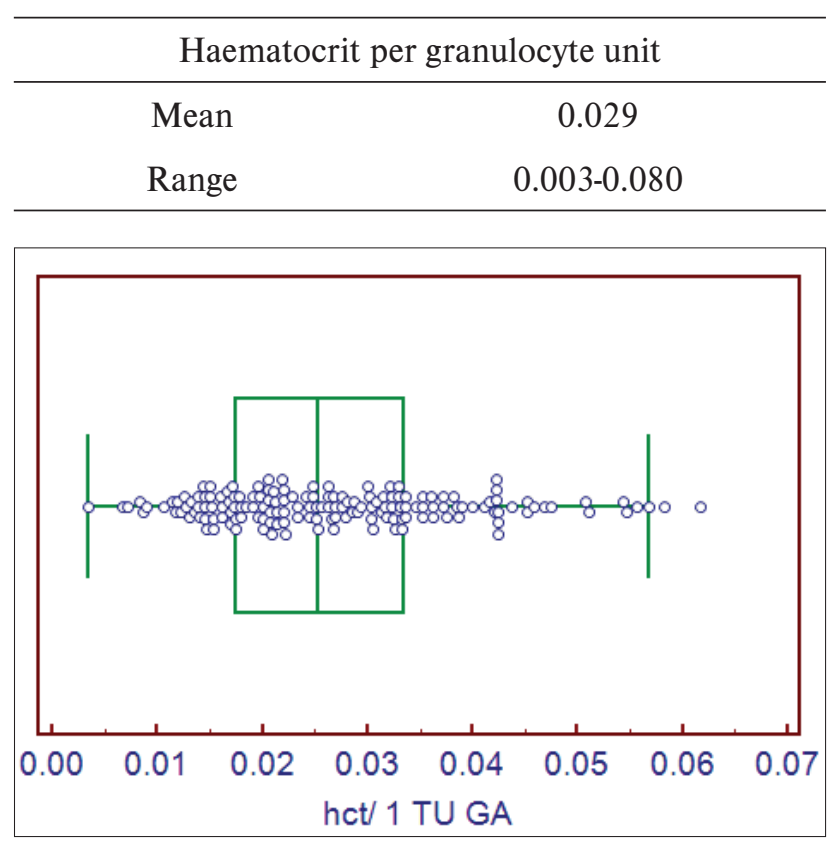

Fig. 1. Box and Whisker graph. Variable haematocrit per TU. Granulocytes were equally distributed around a theoretical midpoint. Although there were some eccentric points, these were still within the tolerance range.

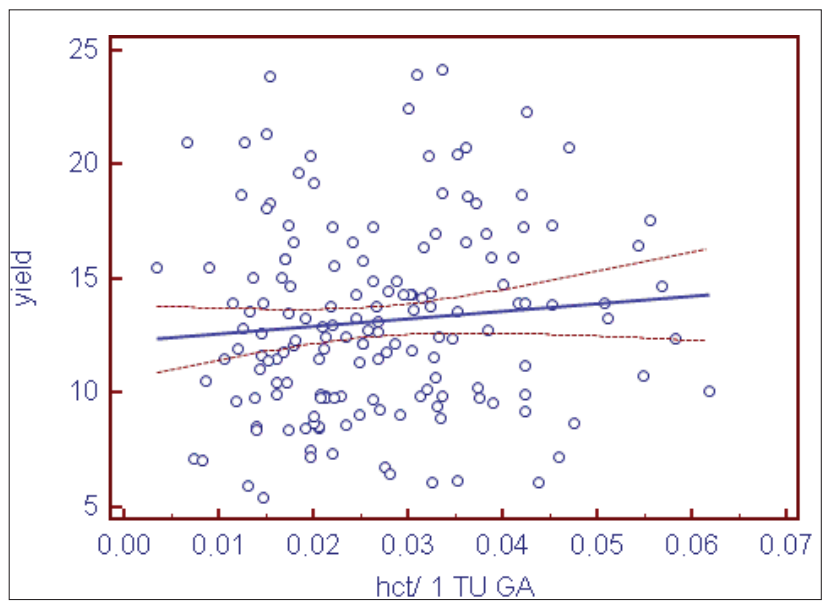

Fig. 2. Point graph of relationship between haematocrit and granulocyte yield. There was no correlation between the haematocrit per granulocyte TU and granulocyte yield. 


\begin{tabular}{|l|l|}
\hline Dependent $Y$ & yield \\
\hline Independent $X$ & $\begin{array}{l}\text { hct_1_TU_GA } \\
\text { hct/1 TU GA }\end{array}$ \\
\hline
\end{tabular}

\begin{tabular}{|l|r|}
\hline Sample size & 158 \\
\hline Coefficient of determination $\mathrm{R}^{2}$ & 0.009058 \\
\hline Residual standard deviation & 4.1296 \\
\hline
\end{tabular}

\section{Regression Equation}

\begin{tabular}{|l|r|r|r|r|r|}
\hline$y=12.2826$ & +33.2231 & & \\
\hline Parameter & Coefficient & Std. Error & $95 \% \mathrm{Cl}$ & $\mathrm{t}$ & $\mathrm{P}$ \\
\hline Intercept & 12.2826 & 0.8173 & 10.6683 to 13.8970 & 15.0290 & $<0.0001$ \\
\hline Slope & 33.2231 & 27.8213 & -21.7319 to 88.1780 & 1.1942 & 0.2342 \\
\hline
\end{tabular}

Analysis of Variance

\begin{tabular}{|l|r|r|r|}
\hline Source & DF & Sum of Squares & Mean Square \\
\hline Regression & 1 & 24.3183 & 24.3183 \\
\hline Residual & 156 & 2660.3046 & 17.0532 \\
\hline
\end{tabular}

\begin{tabular}{|l|r|}
\hline F-ratio & 1.4260 \\
Significance level & $P=0.234$ \\
\hline
\end{tabular}

Table 5. Correlation between haematocrit per TU and yield.
Table 6. Yield and volume of granulocyte apheresis, and separation time.

\begin{tabular}{lccc}
\hline & $\begin{array}{c}\text { Granulocyte } \\
\text { yield }\left(10^{9} / \mathrm{TU}\right)\end{array}$ & $\begin{array}{c}\text { Apheresis } \\
\text { volume }(\mathrm{mL})\end{array}$ & $\begin{array}{c}\text { Separation } \\
\text { time }(\mathrm{min})\end{array}$ \\
\hline Mean & 12.6 & 270.0 & 105 \\
Range & $5.4-30.3$ & $220.0-360.0$ & $90-120$ \\
\hline
\end{tabular}

\section{DISCUSSION}

Granulocytapheresis donors at the Blood Centre Ostrava were healthy volunteers from a pool of apheresis donors; granulocytes were not collected from patients' relatives. The mobilization regimen thus used corticosteroids alone as national guidelines only allow the use of G-CSF mobilization in related donors. However, many European and US centres use this "off-label" administration in unrelated donors ${ }^{2}$. Methylprednisolone 40 $\mathrm{mg}$ in $0.9 \%$ sodium citrate $500 \mathrm{~mL}$ was well-accepted by donors, with no adverse events except for fatigue within $24 \mathrm{~h}$ after collection. Granulocytes were collected a maximum of twice a year. CMV status is not routinely investigated at this institution, because of its tendency to change. CMV-untested donors may be used to support CMV-negative patients if the medical benefits seem to outweigh the potential risks, in accordance with procedures at other blood centres worldwide (e.g., Department of Transfusion Medicine, Bethesda, MD, USA; University of Texas, MD Anderson Cancer Center, Houston, USA). High-molecular-weight HES was used to enhance the efficiency of granulocyte collection during the separation

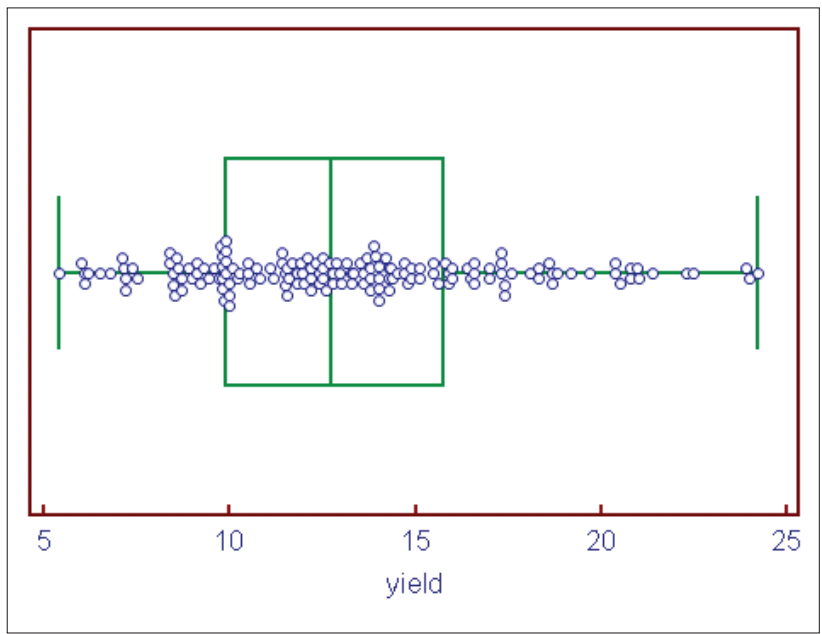

Fig. 3. Box and Whisker graph. Yield was equally distributed around a theoretical mid-point.

process in the current study. Analysis of the distribution of haematocrit per granulocyte TU showed that the collection process was stable, and the haematocrit had no effect on the granulocyte yield ${ }^{3}$. AB 0 and $\mathrm{Rh}$ compatibility between donors and recipients was respected in this study. However, some blood centres do not respect AB0 Rh compatibility, though incompatible red cells are removed from the granulocyte component in these cases ${ }^{4}$. Granulocyte donors were not routinely screened for HLA antibodies in this study, and a different approach was used for routine HLA screening ${ }^{5,6}$. 


\section{CONCLUSION}

Granulocyte transfusions may reduce the mortality risk in patients with severe neutropenia, and thus provide valuable therapeutic support. Further randomized studies are needed to assess the global benefits of granulocyte transfusions, involving close collaboration between clinical departments and blood centres.

\section{CONFLICT OF INTEREST STATEMENT}

The authors state that there are no conflicts of interest regarding the publication of this article.

\section{REFERENCES}

1. Guide to the Preparation, Use and Quality Assurance of Blood Components. $16^{\text {th }}$ Edition 2010. European Committee on Blood Transfusion

2. Leitner G, Panzer H, Reesink HW, Stiegler G, Fischer-Nielsen $A$, Dickmeiss E, Einsele H, Reinl P, Wiesneth M, Coluccia P, Axdorph Nygell U, Halter J, Sigle J, Gratwohl A, Buser AS, Ozturk G. Preparation of granulocyte concentrates by apheresis. Vox Sang 2010;88:567-75.

3. Bryant BJ, Yau YY, Byrne PJ, Stroncek DF, Leitman SF. Gravity sedimentation of granulocytapheresis concentrates with hydroxyethyl starch efficiently removes red blood cells and retains neutrophils. Transfusion 2010;50:1203-9.

4. Narvios AB, Reddy V, Lichtoger B. Method of removing incompatible red blood cells from granulocyte components. Transfus Apher Sci 2006;35:179-80.

5. Strauss RG, Klein HG, Price TH, Lichtiger B, Martinez F, Reesink HW, Panzer S. Preparation of granulocyte concentrates by apheresis: collection modalities in the USA. Vox Sang 2011;100:426-33.

6. Vrielink H, Koopman MMW. Preparation of granulocyte concentrates by apheresis: situation in the Netherlands. Vox Sang 2011;100:344-6. 